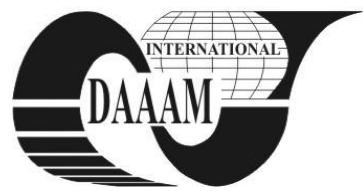

Annals of DAAAM for 2011 \& Proceedings of the 22nd International DAAAM Symposium, Volume 22, No. 1, ISSN 1726-9679 ISBN 978-3-901509-83-4, Editor B. Katalinic, Published by DAAAM International, Vienna, Austria, EU, 2011 Make Harmony between Technology and Nature, and Your Mind will Fly Free as a Bird Annals \& Proceedings of DAAAM International 2011

\title{
TRANSFER OF KNOWLEDGE IN MULTINATIONAL COMPANIES: INTRODUCTION, CONCEPTS AND CONTROVERSES
}

\author{
ADAM, A[drian]
}

\begin{abstract}
This paper attempts to identify the role and the importance of knowledge management in the life of a multinational company $(M N C)$. The study of the factors influencing the transfer of knowledge in such an organization is a relatively recent challenge, with various approaches, especially empirical research sometimes generating contradictory results and many open questions. The types of knowledge, the relationship thereof and its influence on the performance of the organization, as well as concepts such as social network and ,relational embeddedness" within a MNC are approached hereunder. It also treats several controversial topics, little approached or clarified in the specialized literature
\end{abstract}

Key words: multinational company, transfer of knowledge, relational embeddedness

\section{INTRODUCTION}

Today, companies recognize the shortcomings in the implementation of organized knowledge, but on the other hand they are subject to uncertainty regarding the availability of appropriate and effective methods and tools to provide knowledge management. Here one can distinguish between several situations, with theoretical approaches and studies more or less in-depth: knowledge transfer within the company, within alliances or groups of companies, between independent companies, between research institutions or universities and companies and for acquisitions of companies and their embedding into MNC. This latter case seems most offering in terms of challenges they generate and its relative "poverty" of verified solutions and methods in the field.

Gupta and Govindarajan (1991) argue that MNC may be regarded as a network of capital, products and knowledge transactions between units operating in various countries. The same authors discover later (2000) that the main reason why these companies exist is their ability to transfer and exploit knowledge more effectively intra-corporation rather than by market mechanisms.

Tallman (2003) found that over the 90's a transition of the conceptual dominant model of the multinational company occurred from the theories of internalization and economy based on transaction costs to the approach of capabilities by market imperfections or company firms based on knowledge. This paradigm shift entailed the conceptualization of multinational company (MNC) as a network where knowledge is shared and whose existence is conditioned by its ability to transfer, create, integrate and dissipate various types of knowledge in a more efficient manner compared to markets (Kogut et al., 1993).

Foss and Pedersen noted that the main interest in researching knowledge management processes in MNC is the cognitive aspects and the way they can influence the costs of transfer, combination and dissipation of knowledge. Much less attention was paid to the way delegation of authority, incentives, monitoring managers and employees have an impact on the processes of generation, transfer, integration or distribution of knowledge. This lack of understanding of the relationship between organizational design issues and knowledge processes in $\mathrm{MNC}$ has theoretical, empirical and managerial dimensions. Experience has shown that MNCs managers have very little access to theoretically substantiated guidelines when it comes to achieving organizational design in CMNs focused on intensive knowledge.

\section{WHAT IS "RELATIONAL EMBEDDEDNESS"?}

"Relational embeddedness" means the quality of the relationship between two or more organizations. Economic and commercial relations between companies are not limited to rational actions only fit for purpose, namely maximization of gains and minimization of costs. Insofar relationship evolve, they tend to strengthen themselves, thus becoming the basis of mutual trust. It relies on positive experiences acquired during the collaboration. Mutual trust results in a decrease in state of uncertainty and renders the action on partner's own benefit more unlikely. Thus, trust has become a cornerstone of economic action among organizations. With this trust entrepreneurs can gain access to resources that otherwise would have been impossible. Time advantages can also be obtained (economies of time) by strengthening this factor, for example: faster resolution of problems through cooperation, joint learning processes, giving up time-consuming contracts negotiations. Through "embeddedness" a company may get faster and easier access to various markets and more efficient response to changes in business environment (Ellrich, 2006).

Generally, foreign investors provide their subsidiaries with financial and technological resources. But they are not sufficient. Emotional support, management expertise and time are relevant factors to characterize the level of social connections between mother and subsidiary company (Uzzi et al., 2003). The degree of trust between them may vary and this allows access to resources and the common resolution of problems. It also influences the amount of knowledge transferred and the transfer efficiency (Uzzi, 1997). Implementation of systems and procedures by the mother company not only does strengthen control, but also provides communication and understanding of its business philosophy (Kale et al., 2000).

\section{TACIT AND EXPLICIT KNOWLEDGE}

Tacit knowledge is abstract and may be communicated only through the active involvement of the mentor. Explicit knowledge is highly codified and transmissible only through formal and systematic language (Nonaka et al., 1995). In other words, while explicit knowledge provides the building blocks, the tacit one provides the mortar. Although the latter is more valuable, the first is easier to get and may be exploited faster. Generally, development of products, technologies and production processes are rather explicit and may be transferred more easily, while managerial and marketing expertise is largely tacit (Lane et al., 2001). 
Knowledge acquisition involves not only the existence of a high absorption capacity, but also the ability to overcome organizational barriers generated by the social context (Szulanski, 1996). By relational embeddedness these barriers may be overcome and the learning process is facilitated creating a common identity, eventually leading to the exchange of knowledge and the reduction of its acquisition costs (Dyer et al., 2000). If relations are strongly embedded, the mother company is more involved in knowledge transfer processes than clinging onto various legal provisions (Kale et al., 2000).

Relational embeddedness plays three crucial roles in knowledge transfer within the MNC: clarity, control and motivation (Dhanaraj et al., 2004). The same authors found that this type of relationship has greater impact on the transfer of tacit knowledge than on the explicit one as well as the fact that the first directly influences the second. Regardless the age of the subsidiaries, this type of relationship improves the transfer of tacit knowledge. The relationship between the mother company and the subsidiaries is often based on a purchase contract which may turn into a close or special relationship. Nevertheless, trust, the strong connection between the two parties as well as the common values and systems stimulates the transfer of tacit knowledge, the most difficult to transfer form of knowledge. Even though no interdependence could have been set between "trust" factor and the learning process, trust is very important for the transfer of tacit knowledge and less relevant for the explicit.

How do the two forms of knowledge influence the performance of an organization? Dhanaraj and his colleagues argue that only explicit knowledge has a significant impact on performance due to relatively small transfer costs, clarity and procedures. In their opinion, the reasons why tacit knowledge does not play the same role are:

- tacit knowledge within the mother company shall be adapted within the subsidiaries and to the social and cultural environment of that particular country

- tacit knowledge "learning" and use are interrelated, but distinct

- there are inherent difficulties and errors in evaluating the level of acquisition of tacit knowledge

Dhanaraj, as well as Uzzi (1997) conclude that tacit accumulation of knowledge requires time, helps understanding explicit knowledge, and is stimulated by relational and social embeddedness.

\section{DISCUSSION}

It has become almost axiomatic that learning and knowledge is the foundation of understanding how competitive advantage is gained and maintained. However, little research has been devoted to systematic understanding and theoretical framing of how heterogeneous elements of knowledge may be stratified, and distributed, that is structured within a MNC [4]. Studies paid much greater attention to understanding knowledge flows between MNC subsidiaries than understanding the stratification of knowledge stocks along and across the organization. The field seems far from consistent understanding of what a knowledge-based MNC entity means.

Foss and Pedersen also formulated several research challenges that this and other researches shall answer:

- what is the unit of analysis in a knowledge-based approach to the MNC?

- what are the dimensions of the knowledge units (other than discretion) that helps us to understand knowledge transfer costs?

- what are the dimensions of the knowledge units that help us to understand the benefits of knowledge integration?

- how are individuals motivated to share knowledge? What are the micro-foundations of knowledge sharing within and between subsidiaries of MNC?
- what behavioural models research on knowledge transfer processes in MNCs should be based on? Is the rational choice paradigm sufficient or are there sociological models needed?

- how may stimulation and motivation mechanisms be used to enhance the knowledge transfer between MNC subsidiaries? How organizational mechanisms may be used for subsidiaries operating in entirely different cultural spheres?

- how should decision-making authority be distributed within the MCN network if the goal is to optimize knowledge generation?

\section{CONCLUSION}

The above-mentioned authors conclude that the studies on knowledge within MNC should be combined with an analysis of organizational mechanisms as tools of influence of the construction, dissipation and transfer of knowledge resources. Especially important is the role of management and the procedures set up in the process of "forgetting" obsolete or counterproductive knowledge, to replace one piece of knowledge with another one. In this case as well, tacit knowledge generates the greatest challenges. Integration into a social network and relational embeddedness, especially within MNC, are also essential conditions for the successful knowledge transfer process.

\section{ACKNOWLEDGEMENTS}

This work was partially supported by strategic the HRD program ID77265 (2010), co-financed by the European Social Fund - Investing in people, the 2007-2013 Human Resources Development Operational Program.

\section{REFERENCES}

Dhanaraj, C.; Lyles, M. A.; Steensma, H. K. \& Tihanyi, L. (2004): Managing tacit and explicit knowledge transfer in IJVs: the role of relational embeddedness and the impact on performance, Journal of International Business Studies 35: 428-442

Dyer, J. H. \& Nobeoka, K. (2000): Creating and managing a high-performance knowledge-sharing network: the Toyota case, Strategic Management Journal 21 (special issue): 345367

Ellrich, M. (2006): Infoblatt Embeddedness, www.klett.de

Foss, N. J. \& Pedersen, T. (2004): Organizing knowledge processes in the multinational corporation, Journal of International Business Studies 35: 340-349

Kale, P.; Singh, H. \& Perlmutter, H. (2000): Learning and protection of proprietary assets in strategic alliances: building relational capital, Strategic Management Journal 21: 217-237

Kogut, B. \& Zander, U. (1993): Knowledge of the firm and the evolutionary theory of the multinational corporation, Journal of International Business Studies 24: 625-645

Lane, P. J.; Salk, J. E. \& Lyles, M. A. (2001): Absorptive capacity, learning and performance in international joint ventures, Strategic Management Journal 22: 1139-1161

Nonaka, I. \& Takeuchi, H. (1995): The Knowledge-creating Company: How Japanese Companies Create the Dynamics of Innovation, Oxford University Press: New York

Szulanski, G. (1996): Exploring internal stickiness: impediments to the transfer of best practice within the firm, Strategic Management Journal 17(special issue): 27-43

Uzzi, B. (1997): Social structure and competition in interfirm networks: the paradox of embeddedness, Administrative Science Quarterly 42: 35-67

Uzzi, B. \& Lancaster, R. (2003): Relational embeddedness and learning: the case of bank loan managers and their clients, Management Science 49(4): 383-399 